\title{
Lacrimal syringing versus combined lacrimal probing and syringing for treatment of congenital nasolacrimal duct obstruction in children
}

\author{
Bhardwaj $\mathrm{P}^{1}$, Singh $\mathrm{K}^{2}$, Sharma $\mathrm{K}^{3}$, Chalia $\mathrm{D}^{4}$, Pal $\mathrm{S}^{5}$ \\ ${ }^{1}$ Dr. Apoorv Bhardwaj, JR-3 ${ }^{\text {rd }}$ year, RIO, GMC Amritsar, ${ }^{2}$ Dr. Karamjit Singh, Associate Professor, Regional Institute of \\ Ophthalmology, GMC, Amritsar, ${ }^{3}$ Dr. Karan Sharma, Professor \& Head, Department of ENT, GMC Amritsar, Punjab, \\ ${ }^{4}$ Dr. Dharamvir Chalia, Professor \& Head, Department of Ophthalmology, GMC, Amritsar, ${ }^{5}$ Dr. Sat Pal, Professor, \\ Department of Ophthalmology, GMC, Amritsar, Punjab, India.
}

Address for correspondence: Dr. Apoorv Bhardwaj, Email: talkto.apoorv@gmail.com

\begin{abstract}
Introduction: Congenital nasolacrimal duct obstruction (CNLDO) is the most common abnormality of the lacrimal system in the early years of life. Aims and Objectives: To rationalize the applicability of lacrimal syringing alone in comparison to combined lacrimal probing and syringing for the treatment of congenital nasolacrimal duct obstruction in children. Material and Methods: The study was conducted on fifty patients suffering from congenital nasolacrimal duct obstruction randomly selected from the outpatient department of Regional Institute of Ophthalmology, Government Medical College, Amritsar. Results: Majority of cases could be cured by single attempt of combined probing and syringing and cure rate could be enhanced by repeated attempts within $1^{\text {st }}$ two years of life. Conclusion: The overall assessment of the study indicates that although the success rate of gentle lacrimal syringing alone is low yet it is worthwhile to try this least traumatic procedure in each and every child reporting with congenital nasolacrimal duct obstruction under 1 year of age. If lacrimal syringing as a first hand procedure fails, then lacrimal probing along with syringing should preferentially be attempted and may be repeated 2-3 times at a minimum interval of 2 weeks each till the patency of nasolacrimal duct is restored.
\end{abstract}

Key words- CNLDO, congenital, nasolacrimal duct,

\section{Introduction}

Congenital nasolacrimal duct obstruction (CNLDO) is the most common abnormality of the lacrimal system in the early years of life. Abnormalities in the embryological development of the lacrimal system may be responsible for this clinical entity. The nasolacrimal duct usually canalizes at $8^{\text {th }}$ month of fetal life [1]. The ocular end establishes a lumen long before the nasal end and the latter is delayed approximately until birth or a little later [2]. The most frequent cause of congenital nasolacrimal duct obstruction is incomplete canalization of the membranous duct. The diagnosis of this condition is usually straight forward and is easily made on the basis of history and examination and it can also be confirmed in many cases by gently pressing over the lacrimal sac and observing serous or mucopurulent or purulent material refluxing from either puncta.

Manuscript received $15^{\text {th }}$ April 2016

Reviewed: $27^{\text {th }}$ April 2016

Author Corrected: $10^{\text {th }}$ May 2016

Accepted for Publication $25^{\text {th }}$ May 2016
The present study was an endeavour to study the comparative analysis between hydrostatic pressure syringing and lacrimal probing combined with irrigation to relieve nasolacrimal duct obstruction in children (0-3 years). The study was aimed to rationalize the applicability of each of these treatment modalities in various age groups of children. It was an attempt to know the difficulties, success, failure and the complications of these methods of intervention.

\section{Material and Methods}

- The study was conducted on fifty patients suffering from congenital nasolacrimal duct obstruction randomly selected from the outpatient department of Regional Institute of Ophthalmology, Government Medical College, Amritsar. Each affected eye of the patients was considered as a separate and individual case. 
- Inclusion criteria

- Children of both sexes up to 3 years of age were included in the study.

- Each of the selected patients was subjected to complete ear, nose and throat (ENT) examination to rule out any gross bony facial defects and any nasal obstructive pathology.

- Exclusion criteria

- Cases with purulent discharge present at the time of birth and within first seven days of birth.

- Cases with congenital absence of punctum, slit punctum or multiple puncta and lacrimal fistula.

- Cases with congenital facial asymmetry or gross nasal bone deformities.

- Cases with pathological conditions obstructing the nasopharynx.

Pre-operative preparation: Basic pre anesthetic investigations. Oral antibiotic cover (cefotaxim suspension $25 \mathrm{mg} / \mathrm{kg}$ body wt. in 3 divided doses) for 3 days prior to instrumental operative procedure. In each case, an attempt was made to do the operative procedure without general anesthesia just by holding, fixing and immobilizing the head manually by an assistant. In case of failure of manual stabilization of head, the patient was subjected to short general anesthesia and the operative procedure was done.

Operative procedure: The upper punctum was dilated using lacrimal punctum dilator and gentle irrigation of nasolacrimal duct with sterile normal saline using $24 \mathrm{G}$ lacrimal cannula and $5 \mathrm{ml}$ locked syringe was attempted. Any fluid regurgitating through either puncta was noticed keeping the cannula in the same position. The patency of the nasolacrimal duct was ascertained by the appearance of fluid at the nostril or by rapid swallowing of fluid by the child. If it succeeded no further intervention was done and the case was followed up for 2 months. However if gentle syringing failed, then at the same sitting lacrimal probing combined with gentle syringing was attempted. In this procedure, lacrimal probe of an appropriate thickness (4/0 or $3 / 0)$ was introduced through the dilated punctum (preferably upper punctum) down into the horizontal part of the canaliculus and the sac till bony resistance was felt. The probe was gently and firmly pushed downward and laterally till it touches the lower end of the duct.

A membranous obstruction was characterized by lack of resistance to the probe until it reached the lower portion of the nasolacrimal duct at which point an obstruction was encountered that was felt to give way without much resistance. In those cases in which this maneuver also failed, the same procedure was repeated after every 2 weeks (maximum 4 attempts) till the procedure became successful and the patient was asked to come for subsequent follow ups for 2 months at an interval of 2 weeks each. If the procedure did not become successful even after the $4^{\text {th }}$ attempt, it was considered as a failed case.

\section{Results}

50 children with 58 congenital nasolacrimal duct obstruction were included in the study and were reviewed with respect to age, sex, eye involved, age of onset, birth history of the child with special reference to birth trauma, mode of treatment used and its result. Each affected eye of the patient was considered as one case under study. 39 patients presented with clinical manifestations of nasolacrimal duct obstruction within $1^{\text {st }}$ year after birth followed by 8 patients within the $1-2$ years and 3 patients within the 2-3 years after birth. Thus majority of the patients were under one year of age. $90 \%$ of the cases had onset of clinical manifestations within first month after birth, Out of the $90 \%$ cases which had onset within the first month, the majority (48.89\%) had onset of clinical manifestations within first seven days. Out of 50 cases, 31 (62\%) were males and $19(38 \%)$ were females. Thus there was higher incidence among male children as compared to female children. (Table 1)

Table-1: Showing gender wise distribution of the patients with nasolacrimal duct obstruction.

\begin{tabular}{|l|l|l|}
\hline Gender & No. of patients $(\mathbf{n = 5 0})$ & Percentage \% \\
\hline Males & 31 & 62.00 \\
\hline Females & 19 & 38.00 \\
\hline
\end{tabular}

$42(84 \%)$ patients had unilateral involvement and only $8(16 \%)$ patients had bilateral involvement. Out of 31 male patients, $26(83.87 \%)$ patients had unilateral involvement and $5(16.13 \%)$ patients had bilateral involvement. Out of 19 female patients, $16(84.21 \%)$ patients had unilateral involvement and $3(15.79 \%)$ patients had bilateral involvement. Thus maximum number of cases presented with unilateral involvement. 
Out of 50 patients of congenital nasolacrimal duct obstruction, a majority $23(46 \%)$ patients presented with obstruction in the right eye followed by $19(38.00 \%)$ patients in left eye and $8(16.00 \%)$ patients presented with obstruction in both eyes. Since each eye is considered as one case so the total number of cases becomes 58 . Thus in the present study the involvement of right eye was more than that of the left eye.

Out of 58 cases, $16(27.59 \%)$ cases presented with epiphora alone and $42(72.41 \%)$ cases presented with epiphora and discharge. Thus the most common clinical manifestation was epiphora with discharge. (Table 2)

Table-2: Showing incidence of clinical manifestations.

\begin{tabular}{|c|c|c|}
\hline Clinical manifestations & No. of cases $(n=58)$ & Percentage \% \\
\hline Epiphora only & 16 & 27.59 \\
\hline \multirow{4}{*}{$\begin{array}{l}\text { Epiphora with discharge } \\
>\text { Serous } \\
>\text { Mucopurulent } \\
>\text { purulent }\end{array}$} & 42 & \multirow[t]{4}{*}{72.41} \\
\hline & $6(14.28 \%)$ & \\
\hline & $28(66.67 \%)$ & \\
\hline & $8(19.05 \%)$ & \\
\hline Narrow inter-palpebral fissure & 0 & 0 \\
\hline Mucocele & 0 & 0 \\
\hline Lacrimal abscess & 0 & 0 \\
\hline
\end{tabular}

Regurgitation test was positive in $46(79.31 \%)$ cases and it was negative in $12(20.69 \%)$ cases. Thus the maximum number of cases had positive regurgitation test.

Out of the 46 cases with positive regurgitant test, the regurgitant fluid was serous in $12(26.09 \%)$ cases, mucopurulent in $28(60.87 \%)$ cases and purulent in $6(13.04 \%)$ cases. Thus majority of the eyes had mucopurulent regurgitant fluid. The mode of delivery of the child was normal in $35(70.00 \%)$ cases, followed by caesarean section in $13(26.00 \%)$ cases and forceps delivery in $2(4.00 \%)$ cases. Since majority of cases had natural mode of delivery hence no relationship could be established to any instrumental trauma in the causation of nasolacrimal duct obstruction. It indicates that any instrumentation required during the process of parturition does not enhance the chances of nasolacrimal duct obstruction.

The cure rate of gentle lacrimal syringing was found to be only $20 \%$ in the age group of 7 days- 1 year. The cure rate was zero in 1-2 years and 2-3 years of age group. The overall cure rate out of 58 cases of lacrimal syringing alone was $15.51 \%$ of which majority of the cases were under 1 year of age. It indicates that only a small number of cases of congenital nasolacrimal duct obstruction can be cured by lacrimal syringing alone. (Table 3 )

Table-3: Showing cure rate with lacrimal syringing in each age group.

\begin{tabular}{|l|l|l|}
\hline Age group & $\begin{array}{l}\text { No. of cases } \\
(\mathbf{n = 5 8})\end{array}$ & $\begin{array}{l}\text { No. of cases cured } \\
\text { (out of 58) }\end{array}$ \\
\hline 7 days-1 year & 45 & $9(20.00 \%)$ \\
\hline $1-2$ years & 10 & $0(0)$ \\
\hline $2-3$ years & 3 & $0(0)$ \\
\hline Total & 58 & $9(15.51 \%)$ \\
\hline
\end{tabular}

The cure rate after the first attempt in the age group of 7 days-1 year, 1-2 years and 2-3 years was $75 \%, 80 \%$ and $33.33 \%$ respectively. Thus the cure rate in majority of the cases could be achieved after first attempt of combined probing and syringing. Out of 49 cases, $36(73.47 \%)$ cases got cured at first attempt of combined probing and syringing. Only 13 (26.53\%) cases needed repeated probing and syringing and the success rate could be enhanced to $85.71 \%$. Thus it indicates that in a majority of cases in which simple syringing fails to relieve the obstruction, combined probing and syringing is successful even at $1^{\text {st }}$ attempt and the success rate can be enhanced by repeated attempts (maximum 4 attempts). (Table 4) 
Table-4: Showing cure rate with combined lacrimal probing and syringing.

\begin{tabular}{|l|l|l|l|l|l|}
\hline \multicolumn{2}{|l|}{} & \multicolumn{2}{l|}{$\begin{array}{l}\text { Overall cure rate in each age group } \\
\text { (Out of 49 cases) }\end{array}$} \\
\hline Age group & No. of cases & $\begin{array}{l}\text { After 1 } \\
\text { sttempt }\end{array}$ & $\begin{array}{l}\text { After 2 } \\
\text { attempt }\end{array}$ & $\begin{array}{l}\text { After } 3^{\text {rd }} \\
\text { attempt }\end{array}$ & $\begin{array}{l}\text { After 4 } \\
\text { attempt }\end{array}$ \\
\hline 7days-1 year & 36 & $27(75.00 \%)$ & $30(83.33 \%)$ & $31(86.11 \%)$ & $31(86.11 \%)$ \\
\hline $1-2$ year & 10 & $8(80.00 \%)$ & $9(90.00 \%)$ & $9(90.00 \%)$ & $9(90.00 \%)$ \\
\hline 2-3 year & 3 & $1(33.33 \%)$ & $2(66.67 \%)$ & $2(66.67 \%)$ & $2(66.67 \%)$ \\
\hline Total & 49 & $36(73.47 \%)$ & $41(83.67 \%)$ & $42(85.71 \%)$ & $42(85.71 \%)$ \\
\hline
\end{tabular}

$2(03.44 \%)$ cases had punctum laceration, $1(01.72 \%)$ case had false passage formation and $1(01.72 \%)$ case had canalicular tear. Thus out of 58 cases only $4(06.89 \%)$ cases developed minor complications during the procedure with punctum laceration being the commonest.

\section{Discussion}

50 patients having 58 (42 unilateral and 8 bilateral) congenital nasolacrimal duct obstruction were examined at department of ophthalmology, attached to the Government Medical College, Amritsar. Each and every case was selected following the laid down criteria for inclusion and exclusion. The observations in relation to various clinical aspects and the treatment modalities adopted to treat congenital nasolacrimal duct obstruction were made.

Age at onset of symptoms: The present study showed that a majority $(76 \%)$ of cases had onset of clinical symptoms within first 2 weeks after birth and rest of the cases had symptoms before $6^{\text {th }}$ month of age. Riser (1935) observed in his study that the age of onset of epiphora and discharge varied, probably with the observing power of the parents, from 1 week to 6 months, average being 1.5 months [3]. Cassady (1948) found that onset of symptoms occurred before the $10^{\text {th }}$ day of life in $85 \%$ of patients [4]. Guerry and Kending (1962) found 12 instances of congenital impatency, as manifested by epiphora and the presence of mucopus after pressure over the affected sac. In 10 cases $(83.33 \%)$, the epiphora appeared within first two weeks after birth [5]. Ffooks (1962) found that $54.8 \%$ of cases developed symptoms within first 6 days of life, $49.4 \%$ within the first 3 days of life and $6.7 \%$ of the cases had onset of symptoms since birth [6]. Nucci et al (1989) found that all the patients in his study had epiphora and recurrent mucopurulent discharge since the first month of life [7]. The observations in the present study were akin to the observations of Riser (1934), Cassady (1934), Guerry and kendig (1962) and Nucci et al(1989) $[3,4,5,6]$. Thus the various studies indicate that in a majority of cases the onset of clinical manifestations is noticed by the parents usually within 3-4 weeks after birth. It is evident from the above mentioned comparative table that there is almost equal distribution of nasolacrimal duct obstruction between both the sexes $[4,6,8,9]$. In the present study the marginally higher number of male children in comparison to female children might be due to preferential care of the male children in the prevalent social set up in this region.

In the present study $84.00 \%$ of cases had unilateral nasolacrimal duct obstruction. Bilateral involvement was present in $16 \%$ of the cases. Thus the comparison of various studies including the present study indicate that unilateral involvement is more common than the bilateral involvement $[4,6,10,11,12]$.

Family History: None of the cases under study had a positive familial tendency of nasolacrimal duct obstruction. Traquair (1941) suggested the role of heredity in this condition [13]. Cassady (1948) studied 100 cases of dacryocystitis and said that heredity or a familial influence could not have a bearing on this malady. Neither the parents nor their near relatives had a history of dacryocystitis. There were no two children of the same or of related families in the series [4]. Bouzas (1974) emphasized heredity and a familiar tendency as one of the etiologic theories of congenital nasolacrimal duct obstruction [3].

Thus the various studies including the present study indicate that there is no convincing evidence to show that heredity plays any role in the occurrence of congenital nasolacrimal duct obstruction. 
Obstetrical history: In the present study $70 \%$ of the cases with nasolacrimal duct obstruction had natural mode of delivery and only $30 \%$ of the cases had some sort of instrumentation during the parturition process. Thus indicating that mode of delivery of child does not have any relationship to nasolacrimal duct obstruction. No comparative study data was found in the available literature.

The regurgitation test was positive in $79.31 \%$ of cases and was negative in $20.69 \%$ of cases in the present study and this was in accordance with the studies done by Cassady, Koke, Ffooks, Guerry and Kendig $[4,5,6,14]$. Thus in a majority of cases with congenital nasolacrimal duct obstruction, regurgitation test is positive.

Result of lacrimal syringing alone: In the present study, a cure rate of $20 \%$ could be achieved in the age group of 7 days -1 year only. Ciftci et al (2000) reported cure rate of $41.7 \%$ in the age group of $0-6$ months, $33.3 \%$ in age group of $7-12$ months and $12.5 \%$ in the age group of 1-2 years [15]. Tahat et al (2000) reported improvement in $64(64 \%)$ out of 100 eyes [16].

\section{Result of combined Probing and syringing: Broggi} (1959) probed 53 youngsters (67 NLD) between 3 weeks to 3 months of age group with complete success $(100 \%)$ in every case. He stated that the probing should be performed as early as possible after the diagnosis of congenital nasolacrimal duct obstruction is made. [11] In 1950, Koke also favoured early probing if the symptoms had not cleared in a month time. He reported on a series of 116 infants of whom 88 were cured by a single probing and 11 by two or more probing [14]. Baker (1985) reported 860 eyes of children probed without general anesthesia. Only $6 \%$ required a second probing and $0.5 \%$ a third [17].

Katowitz and Welsh (1987) reviewed a series of 427 patients and reported success rate of initial probing of $97 \%$ under 13 months of age and of $54.7 \%$ over 13 months of age [18]. Mannor (1999) reported that increasing age significantly decreased the success rate of probing beyond the age of 1 year [19]. Casady DR et al (2006) reported lacrimal probing was successful in 134 of $173(76.9 \%)$ cases [20]. Cha DS et al (2010) reported that success rate of the initial probing was $80 \%$ for all patients, $82 \%$ in the 6 to 12 month age group, $79 \%$ in the 13 to 18 months age group and $78 \%$ among individuals older than 19 months. The success rate of the second probing was $61 \%$ for all patients, $74 \%$ in the
6 to 12 months age group, $58 \%$ in the 13 to 18 months age group and $17 \%$ among individuals older than 19 months [21].

Medghalchi et al (2014) reported cure rate of $91 \%$ in 912 months of age group, $89 \%$ in 1-2 years of age group and $60 \%$ in 2-4 years of age group [22]. Al-Faky et al (2015) reported cure rate of $84.1 \%$ with probing [23].

Thus many ophthalmologists in the past advocated early probing of nasolacrimal duct to relieve obstruction. In the present study the success rate of combined probing and syringing after $1^{\text {st }}$ attempt was $73.47 \%$, out of which majority of cases were those who reported for treatment within $1^{\text {st }}$ two years after birth. The success rate could be enhanced to $85.71 \%$ by repeated attempts (maximum 4 attempts in this series) in whom patency could not be restored after the $1^{\text {st }}$ attempt of treatment. Thus a majority of cases could be cured by single attempt of combined probing and syringing and cure rate could be enhanced by repeated attempts within $1^{\text {st }}$ two years of life.

Thus the observations in the present study were akin to the observations made by many other ophthalmologists favouring early intervention by combined probing and syringing in the management of cases with congenital nasolacrimal duct obstruction.

\section{Conclusion}

The overall assessment of the study indicates that although the success rate of gentle lacrimal syringing alone is low yet it is worthwhile to try this least traumatic procedure in each and every child reporting with congenital nasolacrimal duct obstruction under 1 year of age. If lacrimal syringing as a first hand procedure fails, then lacrimal probing along with syringing should preferentially be attempted and may be repeated 2-3 times at a minimum interval of 2 weeks each till the patency of nasolacrimal duct is restored.

The repeated attempts enhance the success rate. In expert hands lacrimal probing along with syringing assisted by manual stabilization of head can be adopted as a first hand procedure. Early intervention with this procedure reduces the duration of ailment and also the potential complications associated with prolonged illness. At the same time the risks, complications and the expenses associated with its management under general anesthesia can be minimized to a great extent by manual stabilization of head. Thus the findings of the 
study suggest that if lacrimal syringing fails then a combined procedure like lacrimal probing along with syringing should be opted as modality of the treatment at the earliest possible to avoid inherent complications of prolonged ailment and inconvenience to the child. However more work taking bigger study samples is needed to be done to standardize lacrimal probing and syringing as a preferential modality of treatment for congenital nasolacrimal duct obstruction.

Funding: Nil, Conflict of interest: None initiated.

Permission from IRB: Yes

\section{References}

1. Jackson TL. Moorfields manual of ophthalmology. Mosby. 2008.

2. Bashour M. Nasolacrimal duct, congenital anomalies. eMedicine. June 2009.

3.Riser RO. Dacryostenosis in children. Am J Ophthalmol. 1935;18:116.

4. CASSADY JV. Dacryocystitis of infancy; a review of 100 cases. Arch Ophthal. 1948 Apr; 39(4):491-507.

5.GUERRY D 3rd, KENDIG EL Jr. Congenital impatency of the nasolacrimal duct. Arch Ophthal. 1948 Feb;39(2):193-204.

6.Ffooks OO. DACRYOCYSTITIS IN INFANCY. Br J Ophthalmol. 1962 Jul; 46 (7) : 422-34.

7.Nucci P, Capoferri C, Alfarano R, Brancato R. Conservative management of congenital nasolacrimal duct obstruction. J Pediatr Ophthalmol Strabismus. 1989 Jan-Feb; 26 (1):39-43.

8.NORDLOW W, VENNERHOLM I. Congenital atresiae of the lacrimal passages: their occurrence and treatment. Acta Ophthalmol (Copenh). 1953;31(4):36771.

9.Cha DS, Lee H, Park MS, Lee JM, Baek SH. Clinical outcomes of initial and repeated nasolacrimal duct office-based probing for congenital nasolacrimal duct obstruction. Korean J Ophthalmol. 2010 Oct;24(5):2616. doi: 10.3341/kjo.2010.24.5.261. Epub 2010 Oct 5.

10.Robb RM. Success rates of nasolacrimal duct probing at time intervals after 1 year of age.
Ophthalmology. 1998 Jul;105(7):1307-9; discussion 1309-10.

11.BROGGI RJ. The treatment of congenital dacryostenosis. AMA Arch Ophthalmol. 1959 Jan; 61 (1):30-6.

12.Traquair HM. Chronic dacryocystitis. Arch Ophthalmol.1941;26(2):165-180.d.0.i:10.1001/archopth .1941. 00870140015001 .

13.Bouzas A. Congenital nasolacrimal atresia in infants a higher incidence in primiparas. Ophthalmologica. 1974;168(5):360-5.

14.KOKE MP. Treatment of occluded nasolacrimal ducts in infants. Arch Ophthal. 1950 Apr;43(4):750-4.

15. Ciftçi F, Akman A, Sönmez M, Unal M, Güngör A, Yaylali V. Systematic, combined treatment approach to nasolacrimal duct obstruction in different age groups. Eur J Ophthalmol. 2000 Oct-Dec;10(4):324-9.

16. Tahat AA. Dacryostenosis in newborns: probing, or syringing, or both? Eur J Ophthalmol. 2000 Apr-Jun; $10(2): 128-31$

17. Baker JD. Treatment of congenital nasolacrimal system obstruction. J Pediatr Ophthalmol Strabismus. 1985 Jan-Feb;22(1):34-6.

18. Katowitz JA, Welsh MG. Timing of initial probing and irrigation in congenital nasolacrimal duct obstruction. Ophthalmology. 1987 Jun;94(6):698-705.

19. Mannor GE, Rose GE, Frimpong-Ansah K, Ezra E. Factors affecting the success of nasolacrimal duct probing for congenital nasolacrimal duct obstruction. Am J Ophthalmol. 1999 May;127(5):616-7.

20.Casady DR, Meyer DR, Simon JW, Stasior GO, Zobal-Ratner JL. Stepwise treatment paradigm for congenital nasolacrimal duct obstruction. Ophthal Plast Reconstr Surg. 2006;22(4):243-47.

21. Cha DS, Lee H, Park MS, Lee JM, Baek SH. Clinical outcomes of initial and repeated nasolacrimal duct office-based probing for congenital nasolacrimal duct obstruction. Korean J Ophthalmol. 2010 Oct; 24 (5):261-6. doi: 10.3341/kjo.2010.24.5.261. Epub 2010 Oct 5 . 
22. Medghalchi A, Mohammadi MJ, Soltani Moghadam R, Dalili H. Results of nasolacrimal duct probing in children between 9-48 months. Acta Med Iran. 2014; 52(7):545-51.
23. Al-Faky YH, Mousa A, Kalantan H, Al-Otaibi A, Alodan H, Alsuhaibani AH. A prospective, randomised comparison of probing versus bicanalicular silastic intubation for congenital nasolacrimal duct obstruction. Br J Ophthalmol. 2015;99(2):246-50.

\section{How to cite this article?}

Bhardwaj P, Singh K, Sharma K, Chalia D, Pal S. Lacrimal syringing versus combined lacrimal probing and syringing for treatment of congenital nasolacrimal duct obstruction in children. Int J Med Res Rev 2016;4 (6):964-970.doi: 10.17511/ijmrr.2016.i06.17. 